Bangladesh J. Zool. 41(2): 153-163, 2013

\title{
ENDOPARASITIC HELMINTHS OF TENUALOSA ILISHA IN BANGLADESH IN RELATION TO SEX, SEASONS AND HABITAT TYPE
}

\author{
Aminul Islam Bhuiyan \\ Department of Zoology, University of Dhaka, Dhaka-1000, Bangladesh \\ E-mail: aminul_islam89@yahoo.com
}

\begin{abstract}
Seasonal and sex wise occurrence of endoparasitic helminths were observed from sample collected round the year between January 2005 and December 2007. Some 2667 hilsa (male - 288 and female - 2379) were sampled from freshwater, brackish water and marine habitats. Fourteen species/genera of endohelminth parasites detected from hilsa were Faustula brevichrus, F. ilishii, F. gangeticus, Aphanurus stossichi, Lecithaster indicus, Ilisha parthenogenetica (plercercoid), Otobothrium ilisha (plercercoid), Acanthosentis indica, A hilsai, Goezia bangladeshi, Capillaria sp., Hysterothylacium sp., Camallanus sp. and Porroceacum sp. Out of these 14 helminths, 6 (Faustula spp. Aphanurus stossichi, Lecithaster indicus, Ilisha parthenogenetica, Acanthosentis spp., and Goezia bangladeshi,) had the status of component parasite (prevalence above 10\%). Each species of component parasite has shown its own pattern of distribution over seasons and seasonal distribution of component parasites was found to be different between habitats of the hilsa. In freshwater, the spring and winter samples were found not significantly different from each other. But in summer and autumn, there was a significant difference among each other and between spring or winter. In brackish water mean parasite burden in spring was significantly different from other seasons. In marine hilsa the intensity of parasites in all the four seasons were different from each other. The female fishes were found to be more vulnerable to infection irrespective of the habitats of the host fish, though the differences were little.
\end{abstract}

Key words: Hilsa, helminths, season, host sex, habitat type

\section{INTRODUCTION}

The hilsa shad, Tenualosa ilisha is an anadromous fish available in all the major rivers such as the Padma, Meghna, Jamuna, Shibsa, Bishkhali and Payra of Bangladesh almost throughout the year (Haldar and Rahman 1998). Hilsa migrates towards freshwater during spawning season which commence with the start of southwest monsoons. This seasonal migration may have some effects on its parasites burden.

There may be several factors responsible for temporal (seasonal) fluctuations in parasite infection. Granath and Esch (1983a,b,c) studied parasite prevalence and intensities and observed that parasite recruitment and development can be affected by seasonal changes in water temperatures. Chubb (1979, 1980 and 
1982) added that the availability of infected intermediate hosts as a contributing factor in seasonal fluctuation of parasite infection.

Information on seasonal prevalence, intensity and maturation of fish parasites in tropical environment is scanty. Taxonomy, epidemiology, ecological distribution etc of parasites of hilsa from Bangladesh waters have been reported by Alam et al. 2003, Akther et al. 2004, Bhuyian 2006, Bhuiyan et al. $2007 \&$ 2009. No published information is available on seasonal or sex-wise distribution of parasites of T. ilisha of Bangladesh. Only Pal (1963) worked on seasonal fluctuation of parasites of $T$. ilisha of Hooghly river of India.

This study reports on the seasonal and sex-wise occurrence of the component helminth parasites of $T$. ilisha collected from different rivers of Bangladesh which were ecologically different.

\section{MATERIAL AND METHODS}

For the present investigation Tenualosa ilisha were collected from three different ecological habitats of Bangladesh waters like river (Chandpur $23^{\circ} 14.40 \mathrm{~N} 90^{\circ} 40.73 \mathrm{E}, \mathrm{n}=732$ Aricha $23^{\circ} 46.10 \mathrm{~N} 89^{\circ} 46.83 \mathrm{E}, \mathrm{n}=624$, Paksey $24^{\circ} 04.46 \mathrm{~N} 98^{\circ} 02.15 \mathrm{E}, \mathrm{n}=99$ Sherpur24⒊65N 91 $40.82 \mathrm{E}, \mathrm{n}=110$ ), estuaries

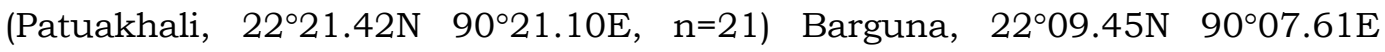
$\mathrm{n}=177$ Bhola, $22^{\circ} 43.10 \mathrm{~N} 90^{\circ} 40.53 \mathrm{E}, \mathrm{n}=154$ ), Barishal $22^{\circ} 42.23 \mathrm{~N} 90^{\circ} 22.49 \mathrm{E}$ $\mathrm{n}=127$ ) and Sandwip 22 $30.56 \mathrm{~N}$ 91.42.78E, $\mathrm{n}=130$ )) and sea (Cox's Bazar $21^{\circ} 25.09 \mathrm{~N} 91^{\circ} 59.97 \mathrm{E}, \mathrm{n}=296$ and Kuakata $\left.21^{\circ} 48.97 \mathrm{~N} 90^{\circ} 07.32 \mathrm{E}, \mathrm{n}=197\right)$. The Global Positioning System (GPS) readings were recorded by Trimble Navigation (Ensign GPS). A total of 2667 (male - 288 and female - 2379) fish were collected from January 2005 to December 2007. Prevalence, intensity and abundance were calculated according to Margolis et al (1982) and component parasites as of Bush et al. (1990).

Fresh fish were collected from the fishermen on the spot as they collected fish except for the Cox's Bazar sample. Frozen fish were collected from this site as the fishermen went out to the deep sea and come back after a week or more. The fish were dissected immediately to obtain the internal organs. The viscera of the fish were removed individually and put in $10 \%$ formalin in polyethylene bags with a label inside. Before they were dissected the weight, length and sex of each fish was recorded. The organs were then brought to the Parasitology laboratory, Department of Zoology, University of Dhaka, Dhaka, Bangladesh. Extensive search was made for helminth parasites infecting the fish. All the parasites from each organ were sorted, cleaned and counted. They were preserved in 70\% alcohol. Berland's (1982) methods were used for staining and mounting. The trematode, cestode and acanthocephalan parasites were stained 
in acetic carmine for 2-3 hours depending on size of specimens. After staining, the worms were washed in $70 \%$ alcohol to which a few drops of glacial acetic acid were added. Then they were cleaned and temporarily mounted in lactophenol for measurements. Nematodes were cleaned and temporarily mounted in lactophenol for microscope study. A few viscera (5-10) were individually put in polyethylene bags and frozen in an icebox and brought to the laboratory from collection sites each time. Parasites obtained from such sample were used for aid in identification. Measurements were taken with the help of an ocular micrometer and a stage micrometer. For quick dehydration Berland (1982) was followed.

Seasons: The groups of successive samplings of each 3 month periods were considered to constitute a season for the purpose of this analysis. However, as there was no gap separating the seasons, this division was used to group the samples broadly into units for temporal comparisons. The seasons were designated as: Winter: November to January; Spring: February to April; Summer: May to July and Autumn: August to October.

\section{RESULTS AND DISCUSSION}

Fourteen species/genera of endohelminth parasites detected from hilsa were Faustula brevichrus, F. ilishii, F. gangeticus, Aphanurus stossichi, Lecithaster indicus, Ilisha parthenogenetica (plercercoid), Otobothrium ilisha (plercercoid), Acanthosentis indica, A hilsai, Goezia bangladeshi, Capillaria sp., Hysterothylacium sp., Camallanus sp. and Porroceacum sp. Under the dissecting microscope three species of Faustula: F. brevichrus, F. ilishii and F. gangeticus., $F$. brevichrus, $F$. ilishii were looked similar. The morphological features became apparent only when the parasites are studied under high (40X) magnification (Leica Zoom 2000 Microscopes). Similarly, both species of Acanthosentis spp. were identified as $A$. indica initially. So when discussing distribution of these parasites, the three species of Faustula have been referred as to Faustula spp. and two species of Acanthosentis as to Acanthosentis. spp.

Of these 14 helminths, 6 (Faustula spp. Aphanurus stossichi, Lecithaster indicus, Misha parthenogenetica, Acanthosentis indica, and Goezia bangladeshi,) had the status of component parasite (prevalence above $10 \%$ ). Only the counts of these 6 component parasites have been calculated on a seasonal basis and sex wise.

Seasonal occurrence of component parasites: Hilsa samples were examined in an attempt to determine any temporal variations that were occurring in the parasite infection characteristics. Figs. 1 \& 2 depict temporal (seasonal) 
variations in the prevalence and mean intensity of the component parasites in the three habitats i. e., freshwater, brackish water and marine hilsa.

Faustula spp.: Prevalence of Faustula spp. in freshwater T. ilisha was higher in both summer $(82.98 \%)$ and autumn $(87.12 \%)$ than in winter and spring. In the brackish and marine hilsa the intensity was high throughout the year and did not fluctuate much over the seasons. It ranged from $88.41 \%$ to $100 \%$ in brackish water and from $85 \%$ to $94.74 \%$ in marine hilsa.

In freshwater and in brackish water T. ilisha highest mean intensity (47.03 \pm 13.87) of the digenean found in T. ilisha was observed in spring. In the marine samples two distinct peaks were recorded in summer $(49.11 \pm 22.54)$ and autumn $(42.48 \pm 19.18)$. It seems that seasonal mean intensity differed clearly between freshwater-brackish water and marine samples of $T$. ilisha. Intensity in freshwater and marine hilsa showed a completely opposite profile (Figs. $1 \& 2$ ).

A. stossichi: In freshwater, peak prevalence (96.84\%) was recorded in winter and lowest $(60.34 \%)$ in autumn. In spring and summer the findings were found almost equal (80.40\% \& $82.98 \%$ respectively). In brackish water bimodal peaks $(100 \% \& 93.62 \%)$ were observed in spring and in winter respectively but in the other seasons it was considerably lower (range $72.73 \%$ - 100\%). In marine $T$. ilisha prevalence peaked in winter and declined gradually as spring came (Figs. $1 \& 2$ ). In all the three habitats the lowest mean intensity was observed in autumn. In freshwater and in brackish water it was higher in spring and winter than summer and autumn. In marine sample the highest intensity was found in winter $(21.33 \pm 7.28)$. The autumn season appeared to be the most favorite time of $A$. stossichi infection in hilsa in all the three habitats (Figs. $1 \& 2$ ).

L. indicus: In freshwater T. ilisha prevalence of infection by $L$. indicus did not vary widely over seasons. It ranged from $39.7 \%$ to $53.72 \%$. In brackish water peak prevalence was observed in the winter, in the other seasons it was almost the same $(54.55 \%-65.22 \%)$. In marine $T$. ilisha prevalence in winter and summer were considerably high. Only $2.5 \%$ of the marine fish were found infected by this digenean in the spring (Figs. $1 \& 2$ ). Both in freshwater and brackish water hilsa the highest mean intensity was occurred in the winter seasons. A second peak was observed in the spring in freshwater sample while in the brackish water sample no second peak was seen. Seasonal trend in terms of mean intensity in marine $T$. ilisha was totally different from that of the freshwater and brackish water samples. Peak intensity was observed in summer, with a second peak in winter. In the other two seasons it was low (1 2) (Figs. $1 \& 2$ ). 
G. bangladeshi: Prevalence of G. bangladeshi was comparatively higher in summer (64.98\%) and in autumn (37.97\%) in freshwater T. ilisha than in the winter and spring samples. In brackish water the highest prevalence $(66.67 \%)$ was recorded in the spring. It declined gradually as the winter approached. In marine $T$. ilisha the prevalence of infection of this nematode was almost equal in most of the time of the year (spring, summer and autumn). However, it was very low $(15.79 \%)$ in the winter sample (Figs. $1 \& 2$ ). Mean intensity did not vary widely over seasons in freshwater $T$. ilisha (range $2.85 \pm 1.09-5.87 \pm 1.89$ ). In brackish water sample exceptionally higher mean intensity observed in spring sample. In rest of the seasons it was almost same. In marine $T$. ilisha mean intensity did not show any pattern, it was higher in spring and autumn than other two seasons (Figs. $1 \& 2$ ).

Acanthosentis spp.: A distinct peak of prevalence was observed in autumn $(12.54 \%)$ sample and extremely low prevalence in winter $(1.27 \%)$ in freshwater $T$. ilisha. In brackish water T. ilisha single peak (12.50\%) was observed in the spring and in the other seasons it was found to be ranged from $1.6 \%$ to $5.8 \%$. In marine T. ilisha no fish was found infected with Acanthosentis spp. in spring and winter collections of $T$. ilisha. In summer and autumn samples prevalence was almost equal (Figs. $1 \& 2$ ). One fish collected during summer in freshwater sample had 354 individuals of $A$. indica, which was the highest intensity in that season. Except this outlier value (354) mean intensity did not vary widely over seasons. It ranged from $1.92 \pm 1.11-2.57 \pm 3.12$. In brackish water and marine samples too mean intensity did vary only slightly and in these sites intensities were close to 1 throughout the year (Figs. $1 \& 2$ ).

I. parthenogenetica: Prevalence was comparatively higher in summer (18.61\%) and autumn (16.61\%) than other seasons in freshwater T. ilisha. Prevalence in brackish water sample did not vary widely. It ranged from $31.55 \%$ to $53.19 \%$. No I. parthenogenetica was found in spring and autumn in the marine sample. Prevalence of $I$. parthenogenetica was much higher in summer than winter in marine T. ilisha (Figs. $1 \& 2$ ). Intensity in freshwater T. ilisha did not show any seasonal trend. It ranged between $2.17 \pm 1.51$ and $8.56 \pm 2.34$. In brackish water sample intensities were higher in autumn and winter than that of spring and summer. In marine T. ilisha mean intensity in summer was higher than that of winter like its corresponding prevalence (Figs. $1 \& 2$ ). It can be concluded that each species of component parasite has shown its own pattern of distribution over the seasons and seasonal distribution of component parasites were differed between habitats of the hilsa. 
Differences in seasonal parasite burden of all the parasites as a whole in the three habitats were observed. Table 1 showed the overall seasonal distribution of the parasites in the different habitats. In freshwater the spring and winter samples were not significantly different from each other. But in summer and autumn there was a significant difference among each other and between spring or winter. In brackish water, mean parasite burden in spring was significantly different from other seasons. In marine hilsa, the intensity of parasites in all seasons were different from each other (Table 1).

Table 1. Parasite burden (means) of the hilsa, Tenualosa ilisha captured during different seasons and habitats

\begin{tabular}{llll}
\hline Seasons & Freshwater & Brackish water & Marine water \\
\hline Spring & $8.444 \mathrm{a}$ & $8.863 \mathrm{a}$ & $3.977 \mathrm{c}$ \\
Summer & $6.306 \mathrm{~b}$ & $6.076 \mathrm{~b}$ & $7.234 \mathrm{a}$ \\
Autumn & $4.035 \mathrm{c}$ & $6.707 \mathrm{~b}$ & $6.320 \mathrm{ab}$ \\
Winter & $8.003 \mathrm{a}$ & $6.747 \mathrm{~b}$ & $5.871 \mathrm{~b}$ \\
\hline
\end{tabular}

Means followed by same letter are not significantly different. $(P<0.05)$.

It could be concluded on seasonal distribution of helminth parasites of hilsa that the component parasites of $T$. ilisha showed temporal variations but no clear patterns were observed in seasonal prevalence or intensity. Faustula spp. and $A$. stossichi showed peak prevalence in winter in all the three habitats, in the other seasons it varied in terms of habitat. Prevalence of $L$. indicus in marine hilsa varied widely over the seasons, in brackish water and freshwater it was almost similar. Prevalence of I. parthenogenetica was higher, round the year, in brackish water hilsa. Lowest prevalence of $G$. bangladeshi was observed in winter in all the three habitats. In other seasons it varied irregularly (Figs. 1 \& 2) probably a sign of continuous recruitment.

Only Pal (1963) worked on seasonal fluctuation of parasites of $T$. ilisha prior to the present study. He found $100 \%$ infection of F. brevichrus in February, March and September and in other months more or less severe infection. Such high intensity was also recorded in the present study. He found plerocercoid larvae of I. parthenogenetica almost throughout the year with $100 \%$ infection in July, August and September. Higher prevalence was occurred in November and December and January to March. Results of present study are consistent with Pal's (1963) findings in the degree of prevalence of $I$. parthenogenetica. Higher prevalence (around 50\%) was observed in brackish water hilsa, lower prevalence in freshwater (around 10\%). Like Pal's findings prevalence did not vary widely over the seasons. But seasonal infection by Acanthosentis spp. did not agree with Pal's (1963) findings. He recorded Acanthosentis indica in a few months only while in present study it could be found throughout the year though the 
prevalence was low. These differences may be due to ecological differences in habitats. As with this study no seasonal pattern was observed by El-Darsh and Whitfield (1999) in Pomphorhynchus laevis (Acanthocephala) infecting flounders from the River Thames which they attributed to a continuous recruitment of the parasite. In T. ilisha, it may be that after intensive ingestion of the intermediate hosts of L. indicus, A. stossichi, I. parthenogenetica in winter and spring in brackish water, the parasite numbers are recorded as highest and most prevalent during these seasons.
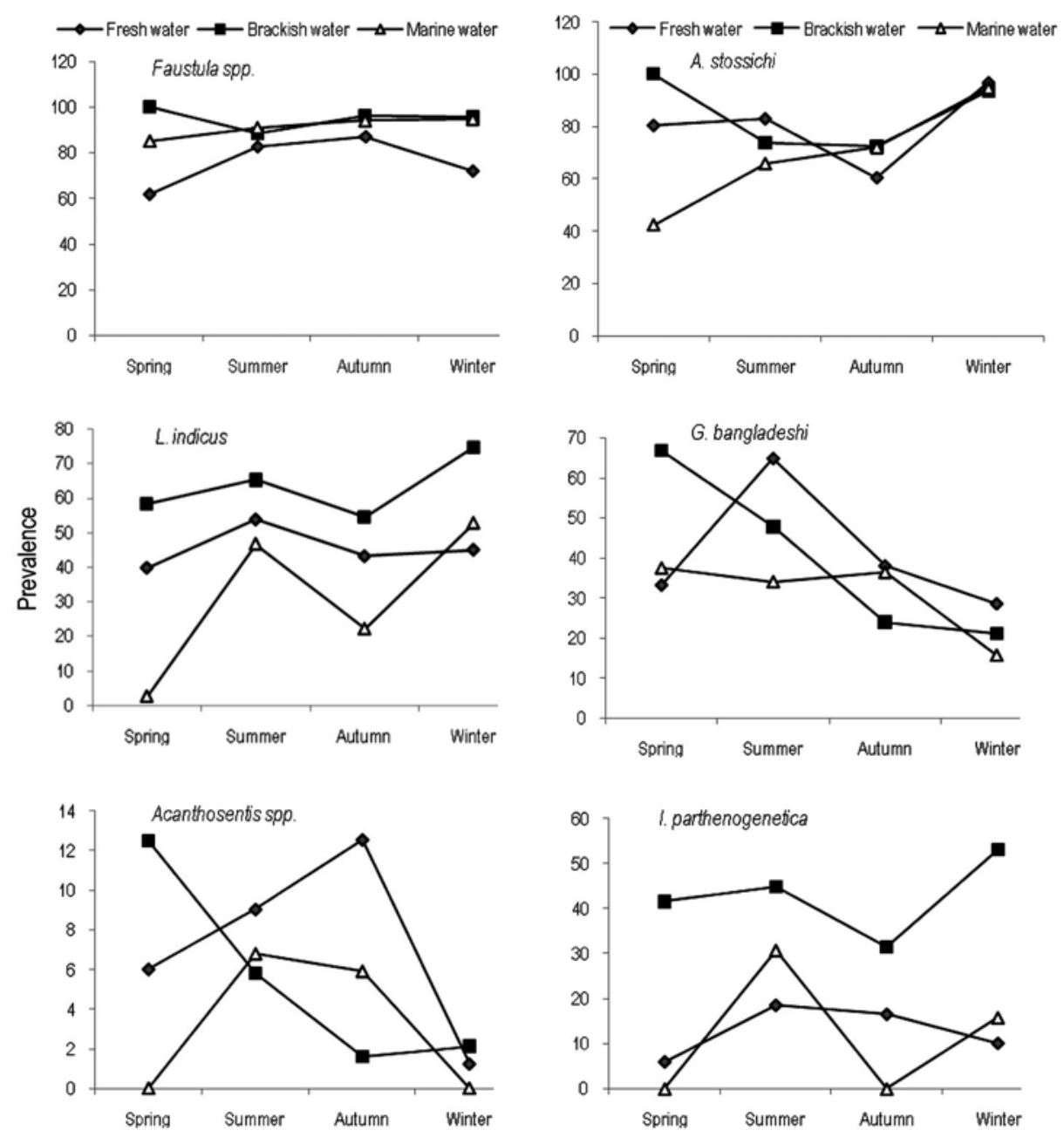

Fig.1. Seasonal prevalence of component parasites of hlsa, Tenualosa ilisha captured from different habitats 


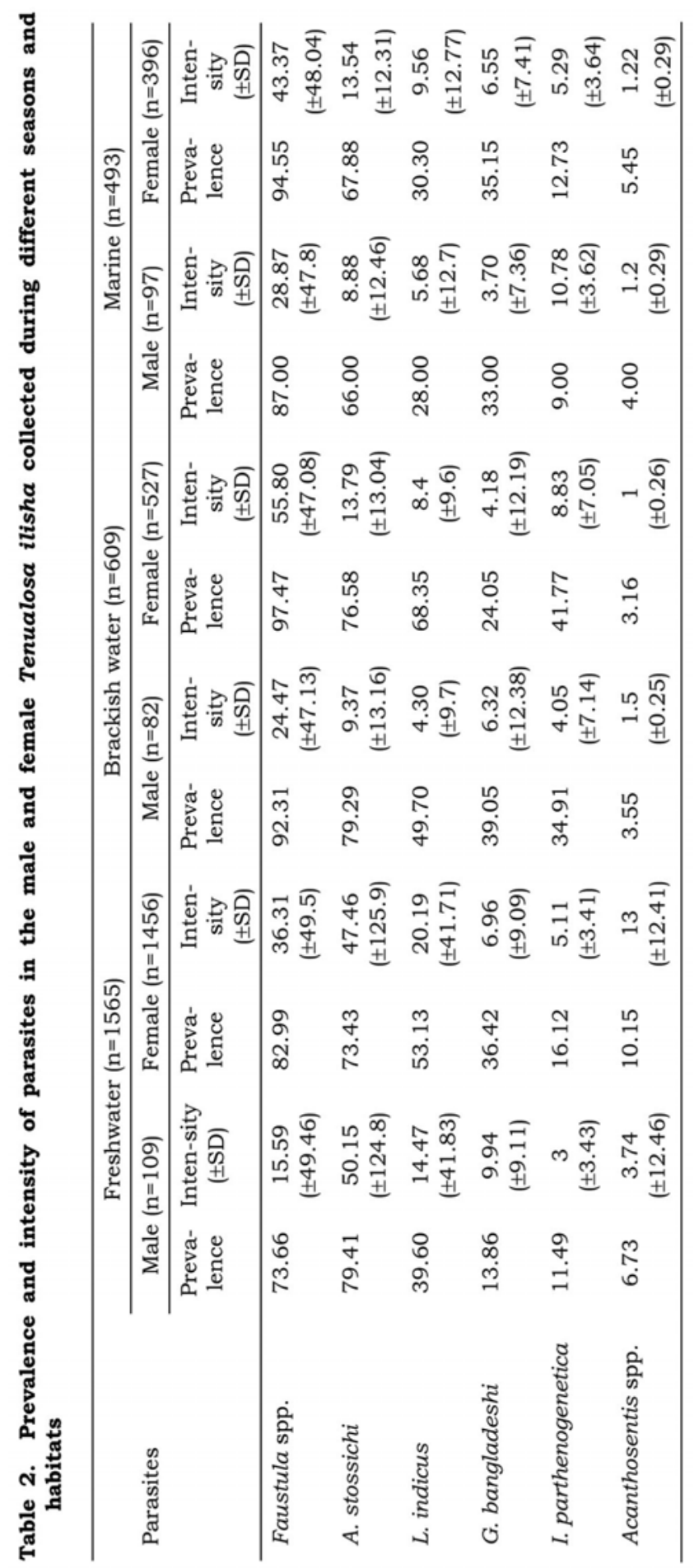


Occurrence of component parasites in male and female T. ilisha: In freshwater both prevalence and intensity of all component species but A. stossichi were higher in female hilsa. Prevalence and intensity of $A$. stossichi were higher in male fish. In brackish water hilsa both prevalence and intensity of infection by Faustula spp., L indicus and I. parthenogenetica were higher in female fish whereas those of $A$. stossichi, G. bangladeshi and Acanthosentis spp. were slightly higher in male fish. In marine hilsa prevalence and intensity of infection of all the component species were higher in female fish but the intensity of $I$. parthenogenetica was higher in male hilsa.
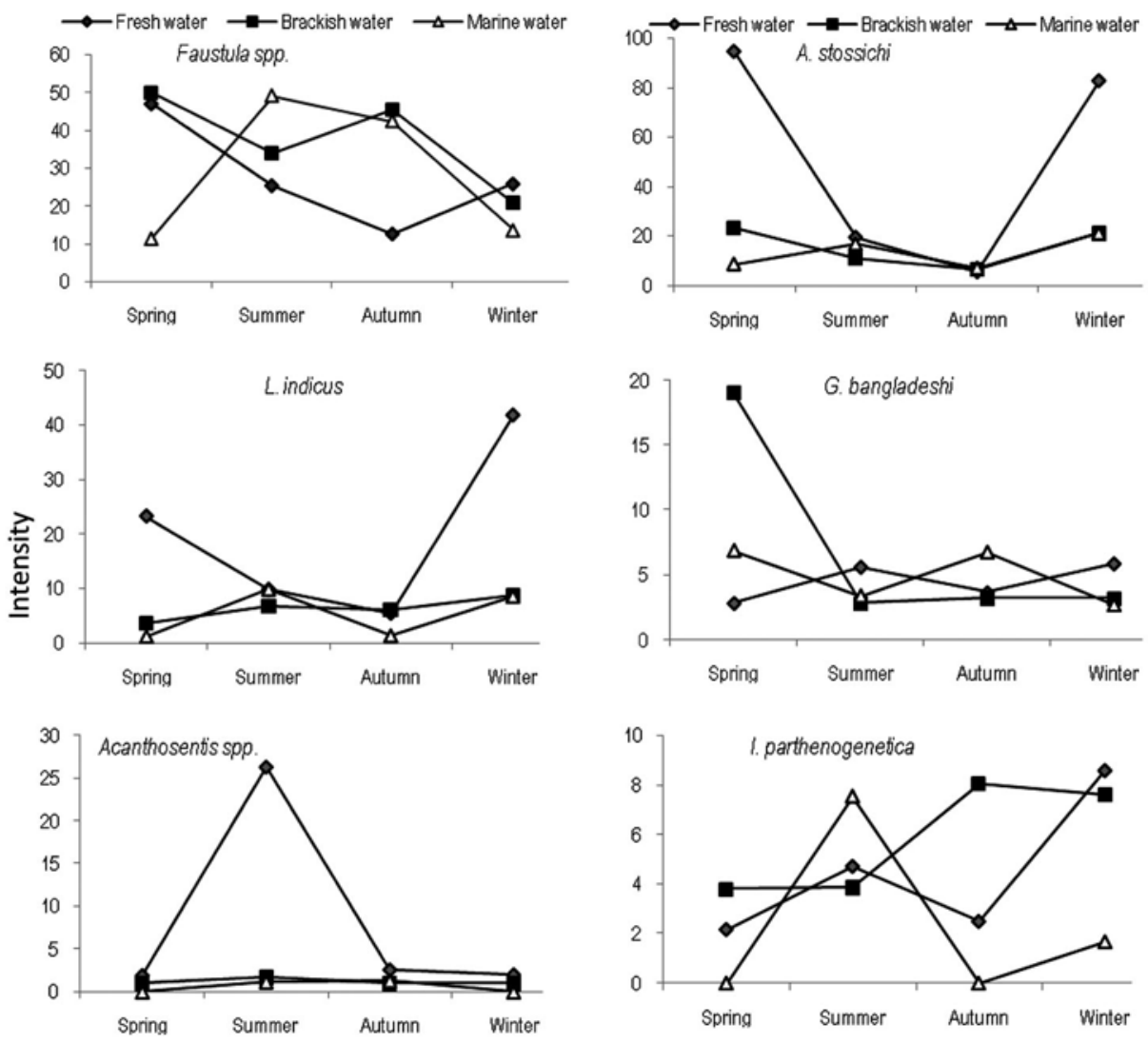

Fig. 2. Seasonal intensity of component parasites of hlsa, Tenualosa ilisha captured from different habitats

It was evident from the results that female fishes are more vulnerable to infection irrespective of the habitats of the host fish, though the differences were little. One digenea, A. stossichi had an affinity for male hilsa of freshwater and brackish water samples. Mean parasite burden was significantly different between the sexes $(\mathrm{F}=3.67, \mathrm{P}<0.05)$. 
Female T. ilisha are more vulnerable to infection in all the three habitats, except for A. stossichi, which had an affinity for male hilsa of freshwater and brackish water. This difference is likely to be attributed to differences in physiological resistance than to differences in the behavioral or ecological resistance of the two sexes. Feeding habit is a vital behavior which plays an important role in parasite acquisition. There are no significant differences in the quality of food eaten by the two sexes. Hilsa of both sexes feeds equally round the year except that for the females do not feed when they are spawning (Shafi et al., 1976). So this non feeding spawning time should have a negative effect on parasite infection in female hilsa but the result is just opposite. It would be expected therefore that both sexes would stand an equal chance or male have a little more favorable feeding habit of being infected by the helminths. Thomas (1964) mentioned the following reasons why mature female are physiologically less resistant than males during and after spawning. First, the condition factor of the females tend to be less than that of the male after spawning which contribute relatively more reproductive materials, expend more energy during spawning and eat less food than the males at this time. Secondly, the state of stress induced by the aggressiveness of the male when spawning might lower the resistance of the female. However, the exact reason for the sex related difference in the prevalence of infection of endo helminths is unknown.

It could be concluded from the above results that each parasite species showed its own seasonal distribution pattern which is different in three different types of habitats. The female fish is more vulnerable to infection in all the three habitats.

\section{LITERATURE CITED}

AKTHER, M., ALAM, A., D’SILVA, J., BHUIYAN, A.I., BRISTOW, G.A. and BERLAND, B. 2004. Goezia bangladeshi n. sp. (Nematoda, Anisakidae) from an anadromous fish Tenualosa ilisha (Clupeidae). Journal of Helminthology. 78: 105-113.

ASMA A., BRISTOW, G.A., D’SILVA, J., AKTHER, M. and BHUIYAN, A.I. 2003. Some endohelminths of the White Sardinella, Sardinella albella (Valenciennes) from Bangladesh. Dhaka Univ. J. Biol. Sci. 12(2): 205-213.

BERLAND, B. 1982. Basic techniques involved in helminth preservation. In proceeding of workshop on "Technology as applied to museum parasite collections." ICOPA V-1982. Toronto, Canada: 115.

BHUIYAN, A.I 2006. Metazoan ectoparasites on the gills of the hilsa shad, Tenualosa ilisha. The Dhaka Univ. J. Biol. Sci. 15(1): 23-29

BHUIYAN, A.I., D'SILVA, J. and BRISTOW, G.A 2007. The metazoan ectoparasite community on the gills of the hilsa shad Tenualosa ilisha (Clupeidae) in Bangladesh. The Dhaka Univ. J. Biol. Sci. 16(1): 1-10. 
BHUIYAN, A.I., D'SILVA, J. and BRISTOW, G.A. 2009. Parasites of Hilsa shad, Tenualosa ilisha in Bangladesh. Bangladesh J. Zool. 37(2): 221-230.

BUSH, A.O., AHO, J.M. and KENNEDY, C.R. 1990. Ecological verses phylogenetic determinants of helminth parasite community richness. Evolutionary Ecology. 4: 1-20.

CHUBB, J.C. 1979. Seasonal occurrence of helminths in freshwater fishes. Part II. Trematoda. Adv. Parasitol. 17: 141-313.

CHUBB, J.C. 1980. Seasonal occurrence of helminths in freshwater fishes. Part III. Larval Cestoda and Nematoda. Adv. Parasitol. 18: 1-120.

CHUBB, J.C. 1982. Seasonal occurrence of helminths in freshwater fishes. Part IV. Adult Cestoda. Nematoda and Acanthocephala. Adv. Parasitol. 20: 1-292.

EL-DARSH, H.E.M. and WHITFIELD, P. J. 1999. The parasite community infecting flounders, Platichthyes flesus, in the tidal Thames. J. Helminthol. 73: 203-214.

GRANATH, W.O. and ESCH, G.W. 1983a. Temperature and other factors that regulate the composition and infrapopulation densities of Bothriocephalus acheilognathi (Cestoda) in Gambusia affinis (Pisces). J. Parasit. 69: 1116-1124

GRANATH, W.O. and ESCH, G.W. 1983b. Survivorship and parasite-induced host mortality among mosquito-fish in a predator-free North Carolina cooling reservoir. Am. Midl. Nat. 110: 314-323.

GRANATH, W.O. and ESCH, G.W. 1983c. Seasonal dynamics of Bothriocephalus acheilognathi (Cestoda) in ambient and thermally altered areas of a North Carolina reservoir. Proc. Helminthol. Soc. Wash. 50: 205-218.

HALDAR, G.C. and RAHMAN, M.A. 1998. Ecology of Hilsa, Tenualosa ilisha (Hamilton). Proce. of BFRI/ACIAR/CSIRO Workshop on Hilsa fisheries research in Bangladesh. 11-19.

MARGOliS, L., ESCH, G.W., HOLMES, J.C. KURIS, A.M. and SCHAD, G.A. 1982. The use of ecological terms in parasitology. (Report of an ad hoc committee of the American Society of Parasitologists.). J. Parasitol. 68(1): 131-133

PAL, R.N. 1963. Observation on fluctuations in parasitisation of the Indian shad, Hilsa ilisha (Hamilton), of the Hooghly estuary. Indian journal of Helminthology. 15(2): 119-126.

SHAFI, M. QUDDUS, M.M.A. and AMIN, R. 1976. The morphology and histology of alimentary tract of Hilsa ilisha (Ham.- Buchanan) with special reference to food and feeding habits. Proc. First. Bang. Sci. Confernce, Dhaka, Bangladesh. Abstract: B-44.

THOMAS, J.D. 1964. A comparison between the helminth burdens of male and female brown tourt, Salmo trutta L., from a natural population in river Teify, West Wales. Parasitology. 54: 263-272 